\title{
Discursos transatlânticos: diálogos entre o Cais das Artes e o Museu dos Coches, de Paulo Mendes da Rocha
}

\author{
Ivo Renato Giroto*
}

Resumo Este artigo tece considerações sobre aspectos da produção contemporânea do premiado arquiteto Paulo Mendes da Rocha através da análise de dois equipamentos culturais recentes: o ainda não concluído Cais das Artes de Vitória (2007), e o Museu Nacional dos Coches (2008-16), em Lisboa, cujas características estimulam uma leitura dialogada. Mendes da Rocha é um dos arquitetos que mais enfaticamente apoiam-se no discurso como suporte da prática arquitetônica, relação que inexoravelmente coloca-se como filtro para a análise das obras. O texto trata, então, não apenas de cotejar discurso e prática, mas o discurso na prática.

Palavras-chave: Paulo Mendes da Rocha, Museu dos Coches, Cais das Artes.

\section{Transatlantic speeches: dialogues between the Dock of the Arts and the National Coach Museum, by Paulo Mendes da Rocha}

\begin{abstract}
This article examines aspects of the contemporary production of the architect Paulo Mendes da Rocha through the analysis of two recent cultural works: the still under construction Cais das Artes (2007), in Vitória, Brazil, and the Museu Nacional dos Coches (2008-16) in Lisbon, Portugal, whose characteristics suggest a dialogic reading. Mendes da Rocha is one of the architects who most emphatically uses the discourse as support of the architectural practice, a relationship that inexorably poses as a filter for the analysis of his works. The text then tries not only to compare discourse and practice, but discourse in practice.
\end{abstract}

Keywords: Paulo Mendes da Rocha, Museu dos Coches, Cais das Artes.

\section{Discursos transatlánticos: diálogos entre el Muelle de las Artes y el Museo de los Coches, de Paulo Mendes da Rocha}

Resumen Este artículo hace consideraciones acerca de aspectos de la producción contemporânea del arquitecto Paulo Mendes da Rocha tras el análisis de dos obras recientes: el aún inconcluso Cais das Artes de Vitória (2007), e o Museu Nacional dos Coches (2008-16), en Lisboa. Mendes da Rocha es uno de los arquitectos que más enfáticamente apoyanse en el discurso como soporte de la práctica arquitectónica, relacción que inexorablemente se impone como filtro para el análisis de las obras. El texto trata, entonces, no solo de cotejar discurso y práctica, sino el discurso en la práctica.

Palabras clave: Paulo Mendes da Rocha, Museu dos Coches, Cais das Artes. 


\section{Para começo de conversa}

A trajetória de Paulo Mendes da Rocha já é bastante conhecida e analisada e, portanto, dispensa grandes apresentações iniciais. Basta dizer que se trata do mais ilustre arquiteto brasileiro vivo, e também do mais premiado. Entre vários outros prêmios e títulos nacionais internacionais, em 2006 ganhou o Pritzker, a honraria mais valorizada do mundo arquitetônico.

Mais que repisar questões gerais sobre sua obra, este texto analisa dois projetos recentes, o ainda não concluído Cais das Artes de Vitória (2007), e o Museu Nacional dos Coches (2008-16), em Lisboa, com o intuito de indagar sobre aspectos da produção contemporânea do arquiteto.

A escolha de dois equipamentos culturais não é fortuita: além de serem as maiores obras de Mendes da Rocha levadas à cabo no século XXI, são representativas da tendência segundo a qual quanto maior o reconhecimento alcançado, maior o número de encomendas para obras icônicas um arquiteto passa a receber.

No refluxo da experiência pós-moderna, o trabalho de Paulo Mendes da Rocha passou por um processo de revalorização dentro e fora do Brasil. No apagar das luzes do século passado, passa a fazer parte do restrito grupo de arquitetos brasileiros com livros monográficos sobre sua obra publicados no exterior, na Espanha (MONTANER; VILLAC, 1996) antes do $2^{\circ}$ prêmio Mies Van der Rohe de Arquitetura Latino-americana (2000), e na Suíça (SPIRO, 2002). Salvo melhor averiguação, antes disso apenas Oscar Niemeyer (PAPADAKI, 1950; 1956; 1960), Rino Levi (LEVI, 1974) e Affonso Eduardo Reidy (1960), ostentavam tal distinção.

Considerado um marco desse processo de renovação do interesse por seu trabalho, o Museu Brasileiro da Escultura - MUBE (1986-95), é apontado como uma de suas obras-primas. Como índice da crescente importância dos projetos culturais em sua produção recente, observa-se que das 33 propostas relacionadas à área cultural ao longo de toda a sua carreira, 25 foram feitas depois do ano 2000 (VILLAC, 2002; PISANI, 2013). Além dos museus em análise, destacam-se o museu infantil SABINA (1999-07), em Santo André; o Museu da Língua Portuguesa (2000-06) e a Praça dos Museus da USP (2010), ambos em, São Paulo; o Museu das Minas e do Metal (2006), em Belo Horizonte; e, alargando um pouco a interpretação, o recém-inaugurado SESC 24 de Maio (2000-17), também na capital paulista.

* Ivo Renato Giroto é Arquiteto e Urbanista, professor da Faculdade de Arquitetura e Urbanismo da Universidade de São Paulo, ORCID <https://orcid.org/00000002-5062-0107>.
Paulo Mendes da Rocha é um dos arquitetos que mais enfaticamente apoiam-se no discurso como suporte da prática arquitetônica, o que inevitavelmente coloca-se como filtro para a leitura da obra. $\mathrm{O}$ artigo propõe uma análise baseada nos discursos e diálogos que os museus estabelecem com as cidades e seus contextos histórico, 
1 Até então, o museu dos Coches tinha como sede um edifício neoclássico vizinho, projetado em 1786 pelo arquiteto italiano Giacomo Azzolini. Convertido em museu em 1905, o antigo prédio apenas tinha espaço para expor um terço das 148 carruagens históricas do acervo.

2 Seis anos após o início da obra, em abril de 2010, a previsão era de que a construção fosse concluída em dois anos. Em 2012, a construtora que executava a obra declarou falência. Em 2013, o governo contratou uma nova empresa que retomou as obras e em maio de 2015, as obras foram paradas por apresentarem suspeitas de irregularidades. Agora, planeja-se inaugurá-lo em meados de 2019. urbano e paisagístico. Também investiga como articulam-se arquitetura e território, funções e técnicas em sua produção contemporânea.

A coincidência de haver dois museus projetados pelo mesmo arquiteto de forma quase simultânea, em dois países separados pelo Atlântico, porém umbilicalmente unidos pela história, intuitivamente sugere uma leitura dialogada. Uma breve análise sobre as relações estruturadoras e discursivas presentes nas duas obras, como se verá, tornam tal sugestão quase irresistível.

\section{Discursos e diálogos}

O Museu dos Coches foi encomendado pelo governo português com o duplo objetivo de abrigar uma vasta coleção de carruagens históricas, e integrar o projeto de transformação de uma das frentes urbanas mais importantes da cidade, a zona Monumental de Belém. ${ }^{1}$ O Cais das Artes foi uma encomenda da Secretaria de Cultura do governo do Espírito Santo, com a intenção de colocar o estado na rota cultural brasileira. Localizada na Enseada do Suá, na entrada da Baía de Vitória, que separa a cidade da vizinha Vila Velha, a área destinada ao projeto é fruto de um grande aterro realizado na década de $1970 .{ }^{2}$

Por detrás dos dois encargos, uma estratégia de política urbana tão recorrente quanto discutível: requalificar áreas urbanas através da implantação de grandes e atrativos equipamentos culturais. Nesses casos, não se trata de áreas em degradação, ao contrário, mas de potencial turístico reconhecido e subaproveitado.

A zona monumental de Belém, em Lisboa, concentra tanto ícones da história portuguesa, como a torre homônima e o Mosteiro dos Jerônimos, quanto obras recentes, como o Centro Cultural de Belém, obra de Vitório Gregotti e Manuel Salgado, inaugurada em 1992. Por sua vez, a Enseada do Suá é a entrada dos portos de Vitória e de Vila Velha e, além de ser geograficamente estratégica, abriga um dos bairros mais nobres da capital capixaba.

O Museu dos Coches ocupa uma área urbanisticamente complexa, exigindo um engenhoso trabalho de amarração entre as diferentes características dos espaços adjacentes: um casario histórico situado na cota mais alta da rua posterior, uma grande praça ajardinada em uma das laterais, e uma movimentada via expressa que separa o terreno da orla do rio Tejo. A área fica exatamente no limite entre os amplos espaços e visuais abertos para as margens do rio e o início do tecido denso da cidade consolidada.

O local escolhido para o Cais das Artes fica na orla da baía, limitando a norte com um entorno ainda horizontal e de caráter residencial, e a oeste com uma grande praça. A situação urbana e paisagística é radicalmente diferente da portuguesa: o entorno urbano é mais rarefeito e menos expressivo, a geografia é dramática, a condição de aterro pressupõe um entorno perfeitamente plano, e o mar define poeticamente um dos limites do terreno.

\section{Sobre a cidade, o supremo museu da humanidade}

Paulo Mendes da Rocha considera a arquitetura um discurso que convoca a totalidade do conhecimento humano, um meio de comunicar valores universais através da técnica 
como atuação política sobre a realidade. Segundo esta visão, uma obra arquitetônica deve atuar como o significante que torna concreto e inteligível o significado abstrato da inteligência.

"Você poderia dizer que arrumar palavras para fazer um poema é coisificar até certo ponto uma ideia, sem dúvida nenhuma. Isso não quer dizer que o raciocínio abstrato não exista, quer dizer que ele só existe quando se coisifica, quando se transforma em discurso público, quando se publica." (ROCHA, 2012, p. 82)

Tanto o Museu dos Coches quanto o Cais das Artes estão assentados em áreas marcadas por uma dinâmica portuária, por si só um vigoroso discurso do empreendimento humano sobre a Terra. Nessa classe de lugar, a história costuma estabelecer um vigoroso diálogo com a geografia, inter-relação que confere uma dimensão extraordinária ao sítio, caracterizado pela confluência do natural com o artificial. Segundo o próprio arquiteto, nascido e criado em Vitória, seu convívio com as atividades do porto da cidade despertou seu interesse e o levou à compreensão da arquitetura como participante dos empreendimentos humanos (ROCHA, 2012, p. 27-29).

Símbolo maior da operação inteligente do homem para criar um planeta habitável, a cidade é, para Mendes da Rocha, o museu vivo da humanidade. A forma como vivemos, ocupamos e construímos o território contém toda a história da inteligência humana, o testemunho de nosso passado e as chaves de nosso futuro. Os museus podem ser âncoras para uma reflexão crítica, mas uma cidade contém um papel didático que nenhum deles pode alcançar.

Em que pese a excepcionalidade desses projetos, a construção do discurso que ampara sua formalização não deriva diretamente do tema em si, mas de uma compreensão mais abrangente do papel da arquitetura na cidade e na sociedade. De fato, a obra de Mendes da Rocha não pode ser categorizada a partir de temas ou programas.

O fato de suas obras mais conhecidas serem museus não intimida um discurso veementemente crítico em relação à proliferação de edificações excepcionais, especialmente em nosso meio.

Não podemos fazer disso um panegírico, em que pretensamente se salva uma cidade com centros culturais e museus. O supremo museu é a própria cidade. (ROCHA, 2012, p. 100)

Para o arquiteto, a construção desses símbolos, tidos como monumentos à nossa civilização, acabam funcionando como um apaziguamento do conflito originário do descaso no enfrentamento dos problemas mais agudos da arquitetura e da sociedade, especialmente a questão habitacional.

Aí a casa você destrata e o museu representa o perdão, uma forma de pedir perdão pelo que não fez ali, então faz aqui. Sempre foi assim. O palácio do rei é uma grande obra de arquitetura e o resto a gente não faz. Cada um que se vire. Ou seja, a grande questão do urbanismo e da arquitetura é política. No fundo, o campo de ação da arquitetura como forma de conhecimento entre nós é o campo político. (ROCHA, 2017) 
Figura 1: Imagem aérea do Museu dos Coches e do Cais das Artes, ainda em construção. Fonte: Esquemas do autor, 2018.
Nessas condições, para Mendes da Rocha a ênfase dada pelo poder público à construção de grandes e icônicos museus seria tão ofensivo quanto discutir nouvelle cuisine diante de uma horda de famintos. No entanto, por mais ácida e contundente que seja tal afirmação, isso não impede que novos museus continuem saindo de sua virtuosa prancheta.

Apesar de tudo, você dizer alguma coisa. Como usar como linguagem a construção, nessa direção que contrariaria tudo aquilo. Entretanto... fasciamo, ancora una volta! (idem)

\section{Sobre integrar e criar contextos}

Uma articulação bastante semelhante resolve a arquitetura dos dois museus: um bloco prismático de caráter horizontal e suspenso por pilotis deixa o térreo virtualmente livre, enquanto volumes menores complementam formal e funcionalmente o bloco principal.

No caso do Museu dos Coches, três volumes conectados por passarelas definem o conjunto. O maior, um grande prisma horizontal branco e suspenso por pilotis abriga os setores expositivos e, no térreo, diversas estruturas de apoio. Ao lado, destaca-se a expressividade estrutural do bloco que abriga auditório, restaurante e setores administrativos. Do outro lado da avenida, um grande silo redondo para estacionamentos, branco e opaco, arremataria o conjunto, mas sua construção foi vetada pelo governo municipal.

O Cais das Artes também é composto por três volumes, sendo um grande volume prismático horizontal destinado às exposições, um grande cubo que abriga o teatro, e um bloco de apoio, menor, posicionado ao lado do setor expositivo.

Um peculiar uso da estratégia moderna de suspensão do edifício libera e integra o ambiente urbano como parte da experiência do museu. Dessa forma, o museu-cidade

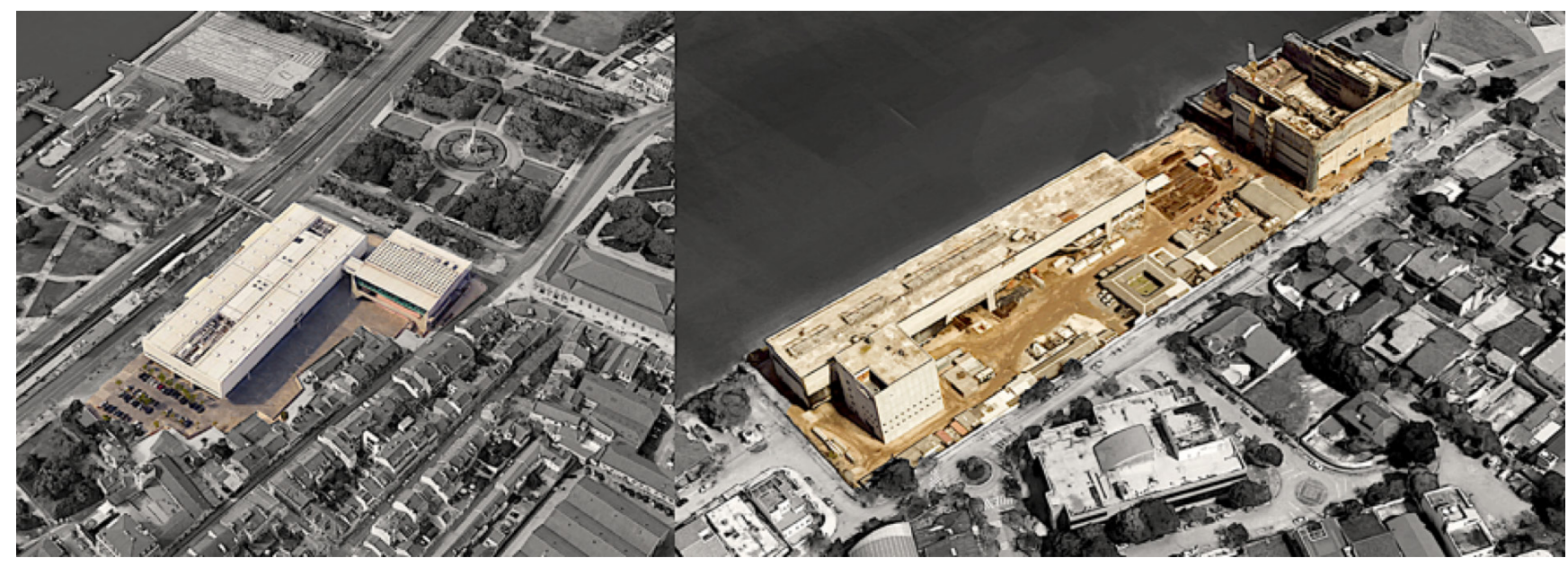


predomina sobre o museu-edifício: a construção não deve "atrapalhar" a dinâmica urbana. Através de espacialidades e enquadramentos engenhosamente compostos, os museus convivem com a cidade de forma a potencializar e revelar seu valor intrínseco.

No Museu dos Coches, a liberação da maior parcela do chão multiplica as possibilidades de percursos das pessoas, sem embotar a percepção do valor museológico presente na própria área urbana de Belém. O Cais das Artes valoriza a conexão com o canal marítimo e monumentaliza a paisagem, ao emoldurá-la cuidadosamente.

No museu lisboeta, a implantação afasta o volume maior do casario, e a posição do bloco lateral contribui para a conformação de um recinto perceptivamente fechado, demarcando uma praça interna de escala bastante agradável, um lugar "rigorosamente protegido e imprevisivelmente aberto" (ROCHA, 2016).

A defasagem entre a cota da rua da Junqueira e o chão da praça reforça uma configuração escalar análoga à das pequenas praças protegidas por edificações das cidades tradicionais europeias. A diferença de níveis também quase elimina a presença visual do térreo envidraçado, parcialmente ocupado por estruturas de acesso e manutenção.

Formalmente mais complexo, o bloco lateral realiza um diálogo com o entorno a partir de fragmentos, cores, cheios e vazios. A relação com a fachada urbana histórica é enfatizada pela abertura de "varandas", situadas em cota semelhante à dos balcões das casas lindeiras, que em futuro próximo imagina-se convertidas em lojas, bares, cafés e livrarias.

Além disso, um volume cúbico interno à estrutura principal desse bloco foi pintado em um tom rosa pálido, bastante assemelhado às cores presentes no casario, "como se dissesse: não se preocupe com essa nova aparição, não é nada mais que a transformação de alguma coisa eterna. A construção da cidade. Agora mesmo." (ROCHA, apud WRIGHT, 2014. Tradução nossa.) Na verdade, o arquiteto lança mão da paleta de cores pálidas e terrosas definida por Artigas e já utilizada em outras obras suas, como na Casa James Francis King (1972-74) e na famosa empena da Casa Junqueira (1976), por exemplo.

Tudo isso demonstra um notável esforço por integrar e integrar-se ao entorno sem, no entanto, fundir-se a ele. O empenho de contextualização baseia-se na consideração do artefato construído como articulador da dinâmica urbana do lugar, e não deriva de suas referências tipológicas ou morfológicas. Como observa Maria Isabel Villac:

E se, na cidade moderna stricto sensu, o edifício se libera da estrutura da quadra, sua autonomia determina a forma urbana de maneira abstrata e gera espaços residuais, a vocação desta modernidade em Mendes da Rocha é contextualizar-se. (VILLAC, 2016)

Segundo Maria Alice Junqueira Bastos, a intrincada relação urbana estabelecida pelo Museu dos Coches reflete uma mudança na forma de inserção urbana de suas obras, com rebatimentos sensíveis no resultado final da arquitetura. Antes da revisão crítica sobre a herança moderna brasileira, levada a cabo nos anos de 1970 e 1980, 


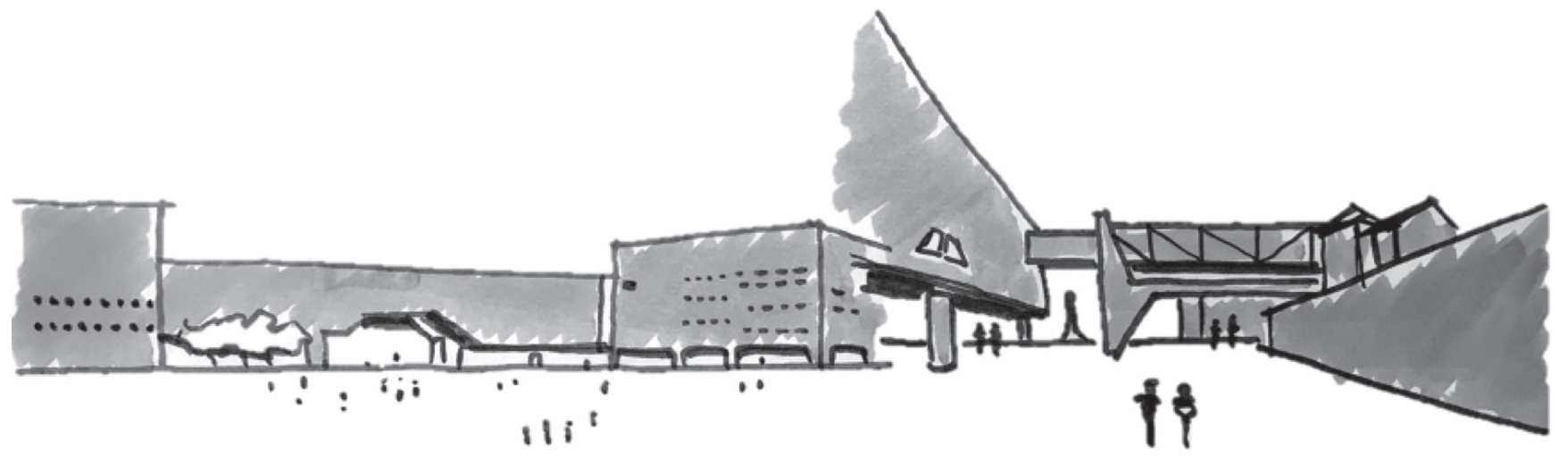

Figura 2: A relação de escala entre as praças do Cais das Artes, à esquerda, e do Museu dos Coches, à direita. Fonte: Croquis do autor, 2018. a arquitetura de Paulo Mendes da Rocha não era notadamente definida pelo lugar urbano, ou preocupada com a configuração de espaços externos. O equilíbrio entre a intenção moderna de generalizar projetos isolados e a busca por uma arquitetura sensível ao contexto fragmentário das cidades é, segundo a autora, tributário deste momento crítico. (BASTOS, 2010)

Apesar das semelhanças no arranjo estruturador, no Cais das Artes a relação com o entorno edificado opera em outra chave. A configuração urbana de casas residenciais isoladas em lotes define uma morfologia dispersa e de pouca altura, o que impede a conformação de uma fachada urbana identificável. Neste caso, mais que contextualizar, a arquitetura busca criar e ordenar um novo contexto.

Entre as duas praças reside uma diferença fundamental: enquanto a pracinha portuguesa sugere convivência e passagem, a esplanada capixba assume um caráter cívico, cuja espacialidade aberta valoriza a leitura monumental do edifício e a contemplação da paisagem.

Ao afastar-se da trama urbana rarefeita para acompanhar a linha d'água, o edifício incorpora o imaginário naval, puxa a cidade para a beira do mar e a coloca de frente para sua razão se ser: o porto.

\section{Sobre construir paisagens e pousar sobre territórios}

Uma questão chave para o entendimento da relação urbana que estabelece o Museu dos Coches é a configuração de percursos "aéreos" definidores da experiência espacial do museu, que se coloca como ponto articulador entre seu interior e o espaço urbano.

Externamente, uma passarela que parte do bloco de apoio vence a obstrução representada pela via expressa e integra-se à estação de trem de Belém, situada no eixo da avenida defronte. Internamente, um caminho suspenso "sobrevoa" os dois grandes pavilhões expositivos e une o bloco principal ao anexo, de onde parte a passarela urbana. Desta forma, o museu não somente integra-se à cidade, como integra a própria cidade. 
Figura 3: O percurso aéreo que define a experiência do Museu dos Coches. Fonte: Esquema do autor, 2018.
A estratégia que dissolve as fronteiras entre arquitetura e urbanismo responsabiliza o artefato construído a fazer parte da infraestrutura urbana. Dessa forma, o entorno físico converte-se em parte ativa da constituição da arquitetura, que se refere a elementos fundamentais do território, e não apenas às circunstâncias de seus limites. (PIÑÓN, 2002, p.9)

O esquema aéreo surge como um critério de desenho adaptável a contextos consolidados e geografias difíceis, energizando e conectando pontos desarticulados do território, ao mesmo tempo que oferece uma ideia prototípica e ideal, adequado também a novas ocupações.

O museu liga níveis e pontos diferentes da cidade, e revela a dimensão urbana do pensamento de Mendes da Rocha, que recusa a ideia limitada de terreno para propor uma estratégia de articulação do território. Catherine Otondo identifica que a compreensão da questão territorial, típica do discurso de Mendes da Rocha, aparece mais fortemente na obra recente do arquiteto, a partir de meados dos anos 90, com a proposta desenvolvida para o concurso da Fundação Getúlio Vargas (1995), sucedida por uma série de projetos como o Centro de Coordenação Geral do Sistema de Vigilância da Amazônia - SIVAM, em Brasília (1998), a primeira versão para os Museus da USP (2000), para a Universidade de Vigo, na Espanha (2003), onde o esquema ganha dimensões monumentais. Nestes projetos não construídos, ela identifica que:

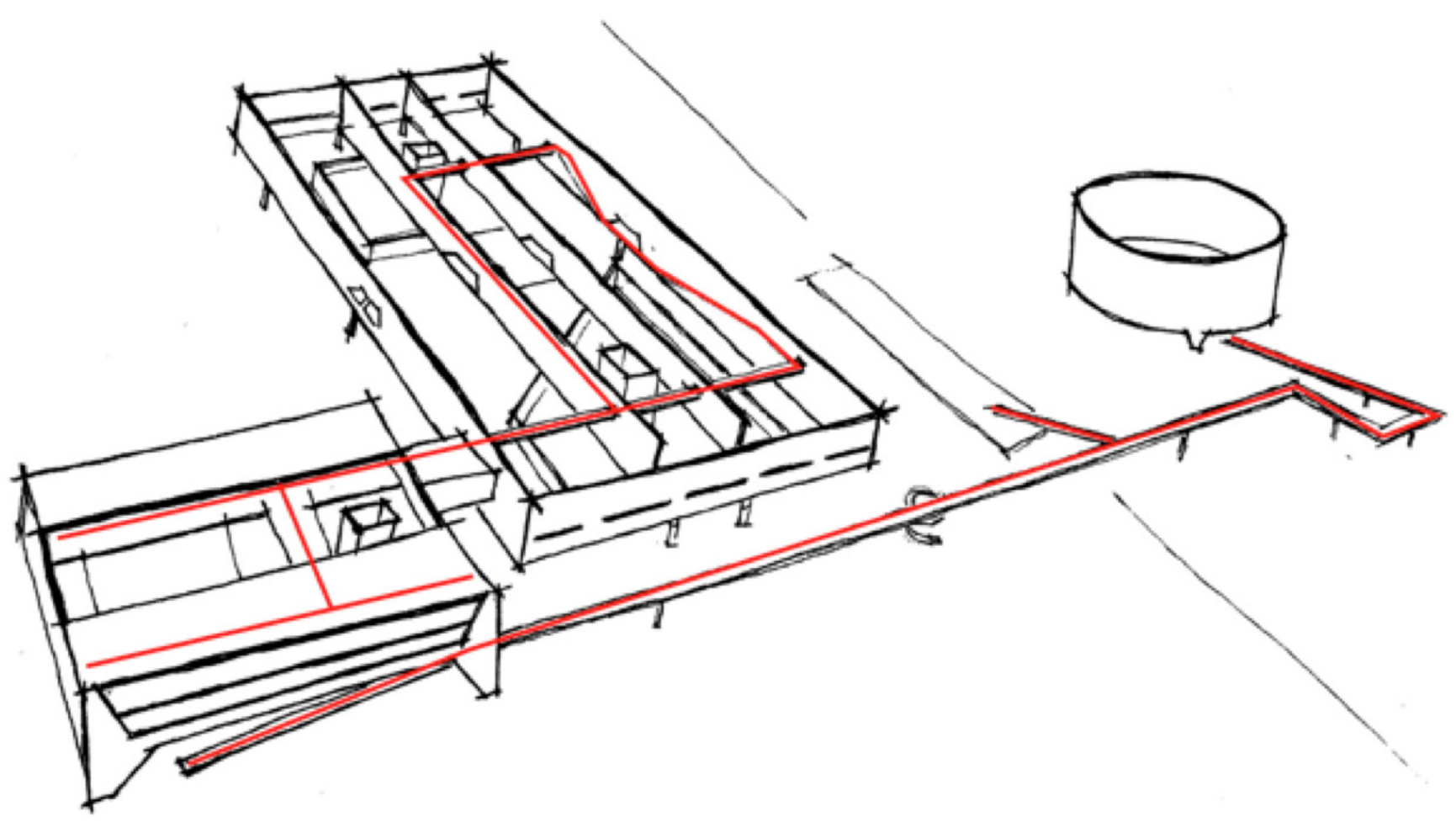


"Em todos eles, a ideia fundamental é criar uma estrutura principal de circulação, em geral aérea, que ordena os fluxos nos diferentes espaços. Como uma veia que alimenta e sustenta essa arquitetura, aparentemente desconexa do chão, desterritorizalizada, como uma alternativa ao real. "(OTONDO, 2013, p. 171-173. Grifo da autora)

De forma mais ampla, tal modelo reflete uma especulação alternativa ao modo de ocupação transplantado na América pelos colonizadores. Amparado em uma leitura geomorfológica, o conceito revela a possibilidade de se construir sobre o território, quase sem tocá-lo, preservando intacta a natureza abaixo desse solo artificial e evitando grandes operações sobre o terreno natural.

Na radicalidade da ideia reside uma compreensão tipicamente americana, mundo novo e campo aberto para as experimentações modernas. O próprio Brasil já havia provado, com a construção de muitas cidades novas, principalmente com Brasília, que novas formas de ocupação eram não somente necessárias, mas possíveis.

Evocando a ousadia de Le Corbusier que, em seus projetos de 1929, enfrentava de forma enérgica a geografia de São Paulo e Rio de Janeiro, Mendes da Rocha integra a experiência europeia à inexorável novidade dos problemas e necessidades do mundo americano, "Porque ao cuidar de modo excelente do seu lugar específico, o homem adquire uma dimensão universal na medida da sua contribuição ao conhecimento." (ROCHA, 1998, in ROCHA; WISNIK, 2012, p. 110)

Uma concepção que deve ser entendida como uma atitude divergente em relação ao sistema de pensamento dos países centrais. De acordo com Marina Waisman, distante de um localismo estreito, resistente, ancorado em uma atitude defensiva em relação ao mundo, a divergência tem um caráter dinâmico, que exprime a dimensão do projeto de forma ampla. "Divergir é desenvolver, a partir daquilo que se é, aquilo que se pode chegar a ser." (WAISMAN, 2013, p. 98)

A ideia de caminhos suspensos aparece discretamente no Cais das Artes, na forma de conexões entre o museu e o volume de apoio. O solo plano e o entorno rarefeito não sugerem a constituição de um sistema de caminhos aéreos, como o que potencializa o alcance urbano do Museu dos Coches.

No Cais das Artes, a articulação do território dá espaço à sua revelação através do confronto da arquitetura com a paisagem. Uma estratégia também evocativa à de Le Corbusier, que definiu seu projeto para o Rio de Janeiro como "O desejo de jogar uma partida a dois, uma partida 'afirmação-homem' contra ou com 'presença-natureza'. " (CORBUSIER, 2004, p. 229).

Em Vitória, o panorama montanhoso confere monumentalidade à paisagem e exige um diálogo mais intenso. O memorial do projeto justifica que "O monumental confronto natureza e construção, neste lugar, sugere os edifícios suspensos no ar e as visuais livres e desimpedidas, para a paisagem e o espetáculo dos trabalhos no mar." (ROCHA, 2012, p. 192)

A amplidão plana do aterro e as perspectivas abertas pelo mar são responsáveis por monumentalizar o conjunto e transformá-lo em escultura na paisagem. Algo que 


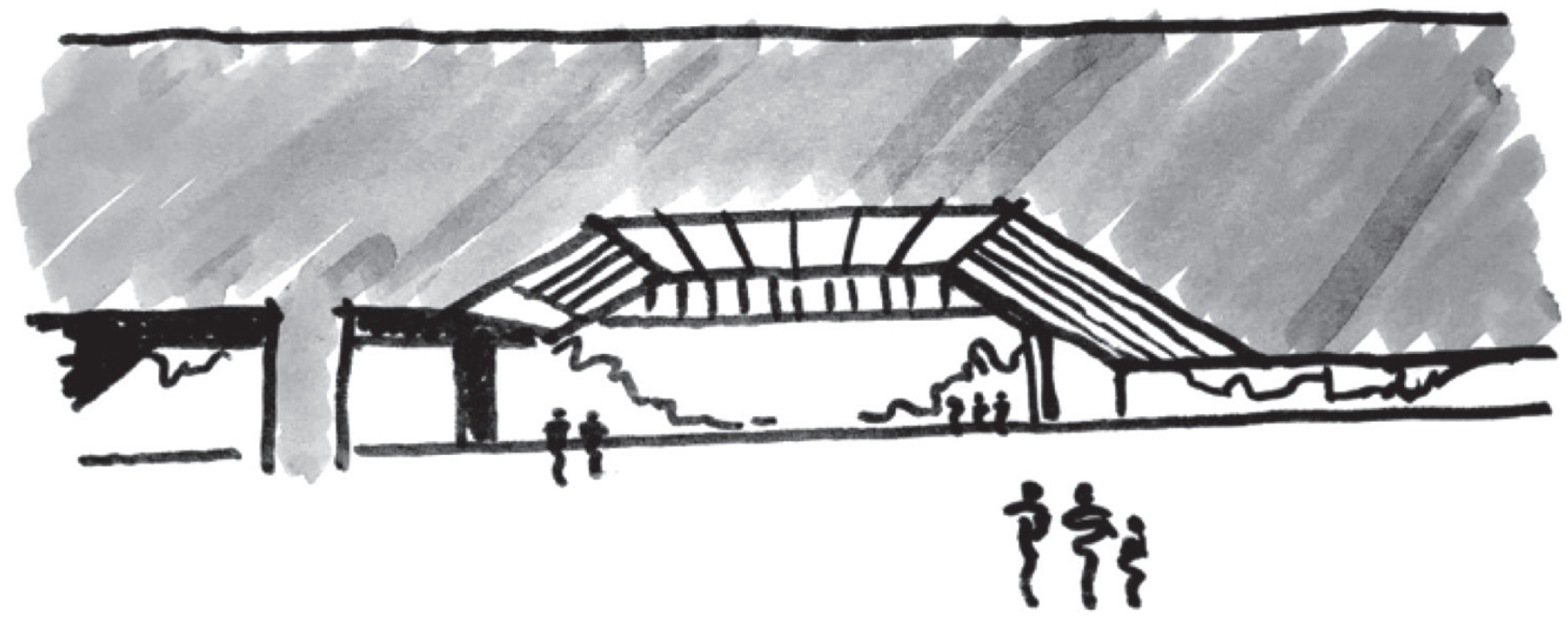

Figura 4: A abertura da vista sob o edifício para valorizar "o monumental confronto natureza e construção". Fonte: Croqui do autor, 2018. as dimensões equiparáveis do Museu dos Coches não são capazes de evocar, dada sua intrincada inserção no entorno urbano. O museu de Lisboa completa um eixo significativo da cidade e qualifica o espaço urbano ao redor; o Cais das Artes propõese como novo símbolo e rosto da cidade de Vitória.

A poética da obra resulta justamente da tensão entre natural e artificial, colocando o ser humano diante de sua própria obra: o aterro, os navios, a transformação do território. As atividades do porto são tratadas como atrativos do museu - talvez o maior deles -, como se fossem parte das coisas por ele expostas.

Ao exaltar o MAM de Reidy, Mendes da Rocha o descreve como o próprio Cais das Artes poderia ser descrito: uma interlocução da impenetrabilidade da matéria, algo em princípio intransponível, que subitamente, como uma visão cinematográfica abre a vista da paisagem monumental enquadrada pelas linhas do edifício. (ROCHA, 2012, p. 57)

Ao investigar porque alguns edifícios são mais interessantes que outros, Kurt Foster destaca a exploração da relação dialética entre artifício e natureza como capaz de gerar uma dinâmica de tensão de grande potencial expressivo (FORSTER, 1999, p. 106). A domesticação da natureza e a reverência à sua monumentalidade estão na raiz da força expressiva do Cais das Artes, amparada na potencialização das características de uma pelo contraste da outra. É justamente na interlocução de duas forças poderosas e, em princípio, opostas, que reside o significado de sua arquitetura.

\section{Sobre tocar o solo e levitar}

Ao analisar uma série de obras da chamada Escola Paulista, a crítica italiana Maria Argenti nota entre suas características principais a exploração da tensão entre a linha do céu e a da terra. 
3 Observações feitas em aula proferida na FAU Maranhão/USP, em 19/12/2016.

Figura 5: Esquemas enfatizando a soltura dos edifícios em relação ao solo. Fonte: Croquis do autor, 2018.
Em muitas arquiteturas paulistas notamos um tipo de inversão da imagem clássica do skyline: o coroamento do edifício parece inexoravelmente linear, enquanto a parte inferior, para o chão, vem incidida, escavada, corroída, retalhada com uma quebra. (ARGENTI, 2014, pp. 57)

Esta estratégia define a volumetria do Cais das Artes, cuja grande barra horizontal prismática passa por uma operação subtrativa de corte irregular que, sem sua parte inferior, parece levitar. A segmentação de seu perfil dinamiza a forma sem perturbar seu semblante tranquilo. O volume cúbico do teatro também se levanta sutilmente do solo, e virtualmente desafia sua materialidade pesada avançando sobre a água do canal. Apenas o pequeno prisma vertical de apoio ao bloco do museu, de caráter claramente secundário, assenta-se diretamente no solo.

No Museu lisboeta a imaculada caixa branca delicadamente apoiada sobre pilotis define o museu como um estojo protetor de preciosidades. No bloco anexo, a elegância da estrutura se dá pelo estiramento acrobático da parte horizontal da estrutura de concreto, que evoca a estrutura do Palácio do Planalto, de Oscar Niemeyer (1954-60).

Já notada por Sophia da Silva Telles, a ênfase na parte inferior das obras é uma característica da arquitetura moderna brasileira, responsável pela tensão entre peso e leveza. Note-se que enfocar a relação da obra com o solo é diferente de suspendê-la por pilotis, como fazia Le Corbusier sem deixar de privilegiar uma leitura volumétrica da arquitetura. ${ }^{3}$ No caso brasileiro a força poética das obras está nos interstícios vazios e no toque delicado e quase impossível da massa edificada com a linha da terra.

A tradição politécnica que está nas bases da formação arquitetônica paulista atribui grande valor à abordagem técnica como forma de materializar a abstração e o sentido contraintuitivo que expressa o cálculo estrutural. Pontes, viadutos, túneis e barragens que construíram a paisagem técnica de São Paulo estão marcadas indelevelmente na iconografia de uma arquitetura que se apresenta como infraestrutura urbana.
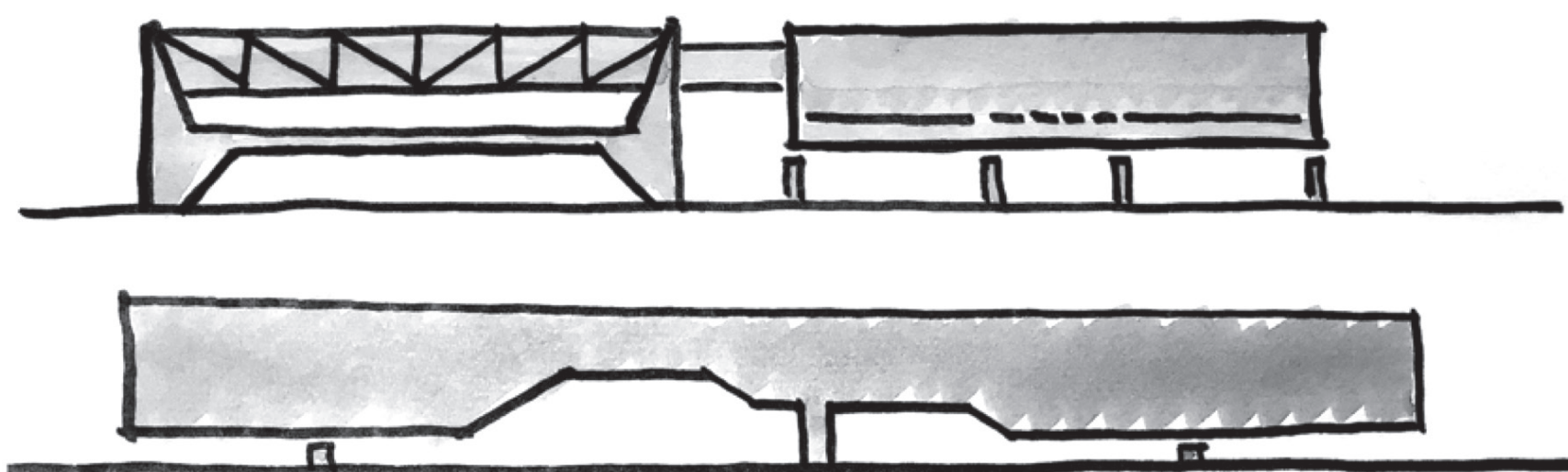
A mesma Sophia Telles já havia chamado a atenção à outra característica central do desenho de Mendes da Rocha, extensível à grande parte da produção paulista: a proeminência do corte como instrumento estruturador da arquitetura. (TELLES, 1990, p. 45). Porém, a virtual ausência de matéria que caracteriza a fusão entre topografia e obra no MUBE contrasta com a forte presença dos grandes volumes suspensos dos museus de Lisboa e Vitória.

No Cais das Artes, o recorte em sua parte inferior evidencia essa relação sincrônica entre estruturação em corte e operação subtrativa. Em concordância com o desenho exterior, os níveis interiores abrem fendas que permitem ver o chão da praça ao mesmo tempo em que recebem a iluminação indireta do sol rebatido no piso. O museu olha a cidade, e a cidade olha o museu

A linha horizontal, pacata, que acompanha a linha d'água define a impostação paisagística do projeto como um monumento que se pretende símbolo e lugar da experiência pública. Uma grande infraestrutura portuária presente física e afetivamente na memória dos habitantes dessa "cidade naval", em palavras do próprio arquiteto.

A forma irregular de seu perfil tem ascendência direta no Centro Krajcberg de Arte e Natura, projetado para a mesma cidade, em 1993. Neste projeto não levado a cabo, grandes e eloquentes gruas portuárias suportariam o volume recortado do museu.

É digno de nota a presença expressiva que as circulações entre pavimentos assumem ao extrapolar para a parte exterior dos volumes principais. Nos dois casos, adossadas à fachada longitudinal oposta à praça/esplanada desenham rigorosamente sua forma funcional, sem deixar margem para dúvidas sobre o que são e para que servem.

\section{Sobre amparar a imprevisibilidade da vida}

Em Paulo Mendes da Rocha, as exigências corriqueiras de um programa de necessidades não são definidoras da arquitetura. O importante é que a solução final traduza, em termos de forma e espacialidade, um elogio da maneira como foi resolvido o problema. Segundo Piñón, em Mendes da Rocha "o programa estabelece as condições da solução, mas não estabelece a natureza do problema" (2012, p. 10).

Internamente, a predominância de uma espacialidade contínua e ininterrupta corresponde-se, externamente, com a liberdade das praças cobertas. Em tudo, a evocação do espaço público democrático e imprevisível, no qual somente a ação do povo irá inaugurar e caracterizar o lugar.

O que desenha a imprevisibilidade da vida é uma construção, nítida e rigorosamente técnica, mas que não determina fim, modo e meio, programa. Ampara a indeterminação, a imponderabilidade da liberdade individual. (ROCHA, in: ARTIGAS, 2000, p. 171-172)

É o caso do sistema de conexão cidade-museu desenvolvida em Lisboa, que transforma a experiência da visita em uma promenade architecturale integral. Os visitantes acessam o museu pelo térreo da praça, por elevadores que os levam até o piso principal, onde podem apreciar os coches expostos em amplos pavilhões. Ao subir pelas escadas laterais, 

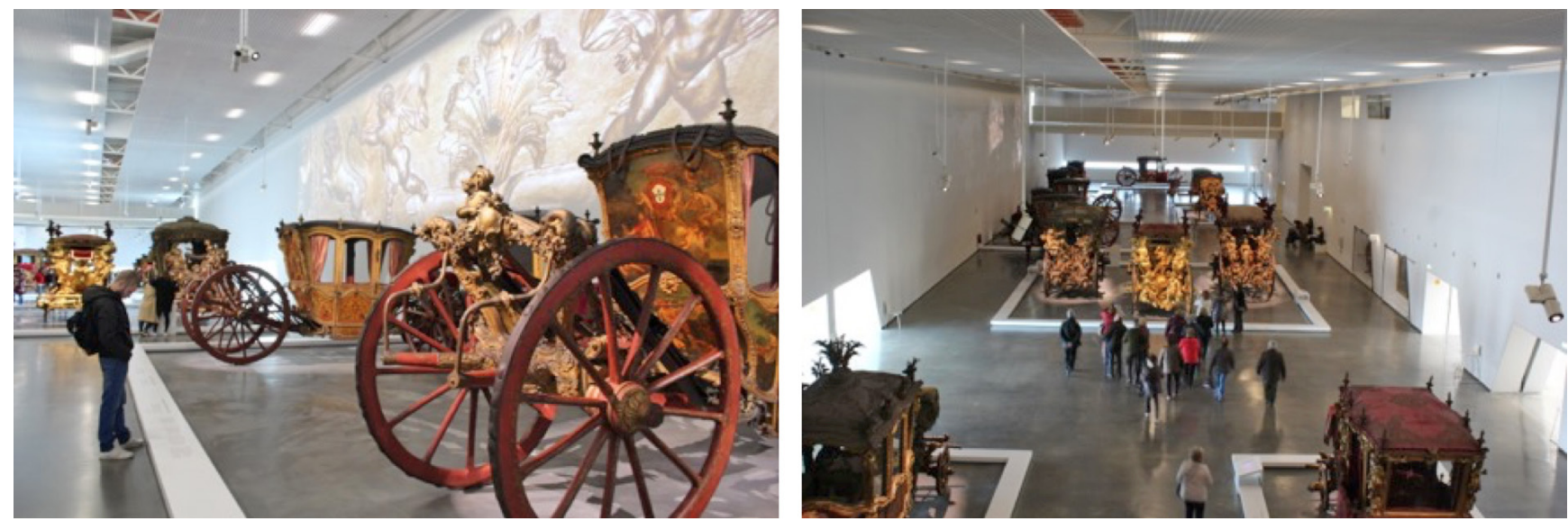

Figuras 6 e 7: As possibilidades de vista dos pavilhões expositivos do Museu dos Coches. Fonte: Fotos do autor, 2018. penduradas externamente ao volume principal, circulam por uma passarela aérea que permite um instigante passeio à vista de pássaro, abrindo ângulos e perspectivas impossíveis à altura do observador. Finalmente, o caminho suspenso conecta o museu ao restaurante e áreas administrativas, situadas no último pavimento do bloco anexo, que ainda conta com o auditório logo abaixo.

Apesar de a passarela urbana não possuir conexão direta com a interna, por questões de segurança e controle de acesso, percebe-se que a dinâmica de fluxos é o elemento articulador da funcionalidade e da espacialidade do museu, marcadas pela constituição de percursos definidos por estruturas mínimas.

No térreo mais livre do Cais das Artes, uma rampa aberta ao espaço circundante leva os visitantes à recepção no primeiro pavimento, de onde arranca outra grande rampa, externa ao bloco do museu, que conecta todos os espaços expositivos, distribuídos por três pavimentos. A locação de escadas e rampas externamente ao volume resguarda a fluidez espacial dos grandes pavilhões longitudinais.

No museu português, a barra longitudinal de 126x48m divide-se em duas amplas alas, separadas por um septo que concentra toda a estrutura de apoio e coincide com a modulação estrutural dos pilotis centrais. Em Vitória, uma espacialidade qualificada pela interação entre os vazios de pavimentos interrompidos fisicamente e conectados visualmente preenche o pavilhão de 150x25m. Em ambos, a espacialidade tão legível quanto instigante estimula o visitante a explorá-la.

A especificidade de cada uma das raras carruagens que compõem o acervo do Museu dos Coches é valorizada pela neutralidade branca e indiferenciada dos etéreos salões de exposição. A museografia distribui as peças de forma habilidosa pelos amplos pavilhões, evitando que as carruagens pareçam soltas no amplo espaço, e aproveita as grandes paredes como superfícies para projeção.

No cais das Artes, as diferentes cotas entre as lajes foram desenhadas de modo a permitir uma lúdica multiplicidade de pontos de vista e perspectivas dos espaços banhados pela luz indireta proveniente da praça. A definição de recintos de alturas e dimensões variadas procura adaptar-se a um acervo ainda incógnito. 


\section{Entre ver e entrever}

O caráter diáfano dos pavilhões onde a brancura predomina, contrasta com a luz pesada e a ambientação marcada pela aspereza tátil do concreto bruto da maioria das obras de Mendes da Rocha anteriores aos anos 1980. Na penumbra e na luminosidade habilmente controlada dos interiores o arquiteto costuma explorar texturas e materialidades, e conceber espaços de dimensão fenomenológica, como atestam o MUBE e a Pinacoteca.

Esta qualidade perde parte de sua dramaticidade em função da iluminação controlada dos museus, porém resiste no inteligente esquema de luz rebatida do museu capixaba e, especialmente, no jogo de luzes, sombras e reflexos proporcionado pela cobertura transparente do prédio de apoio. Ao longo do dia, a trajetória solar vai desenhando uma trama de polígonos que se movem sobre a lâmina d'água que cobre o auditório, produzindo um estimulante efeito perceptivo que potencializa o efeito luminoso das típicas grelhas nervuradas paulistas.

Figura 8: O instigante jogo de reflexos no espelho d'água sobre 0 auditório do Museu dos Coches. Fonte: Foto do autor, 2018.
Uma questão notável nos dois projetos reside na diversidade de pontos de vista e enquadramentos que oferecem aos visitantes. Externamente, o arranjo volumétrico abre frestas por debaixo e entre os blocos, emoldurando trechos da paisagem e do

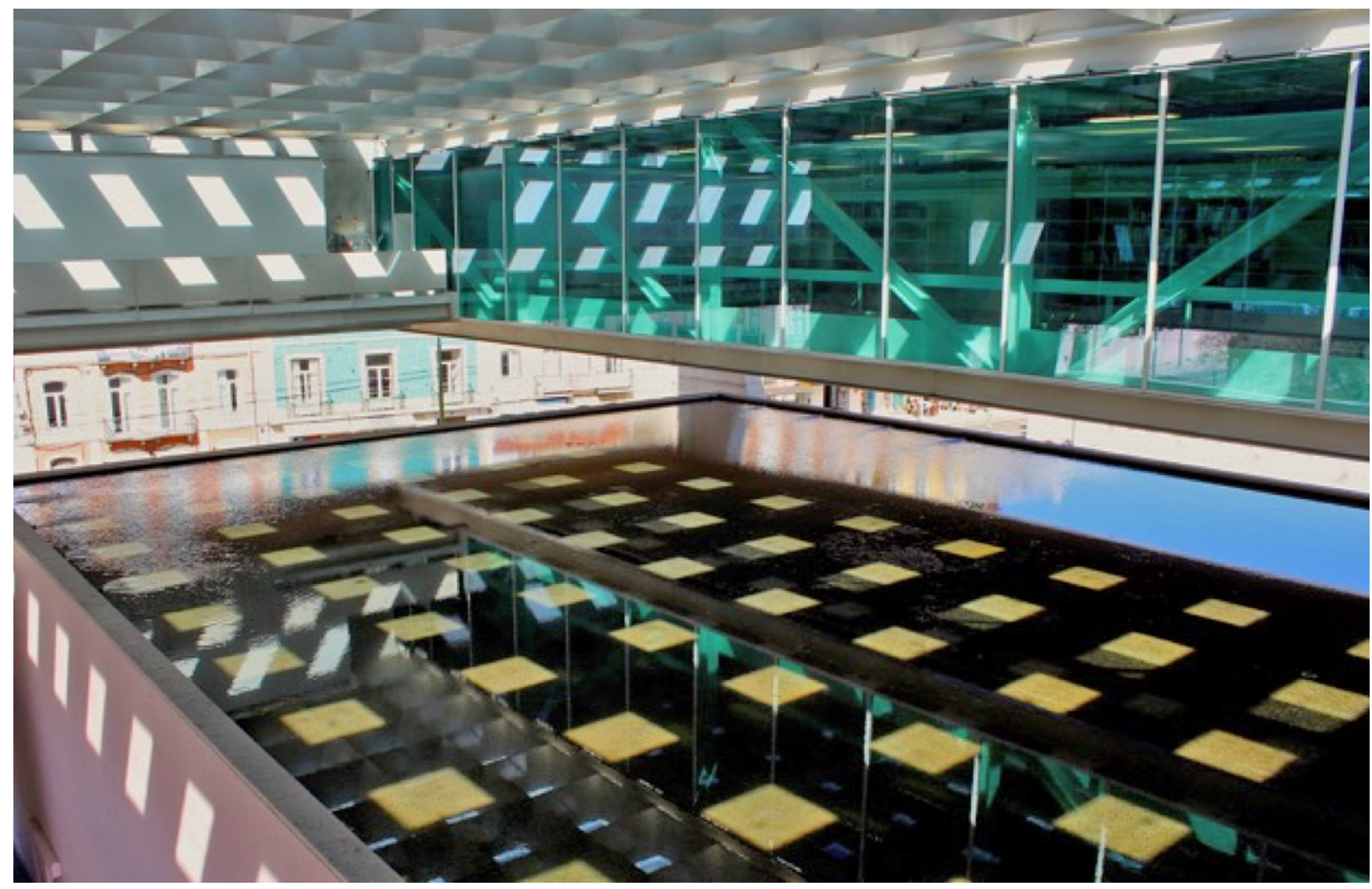

risco. 17_1 


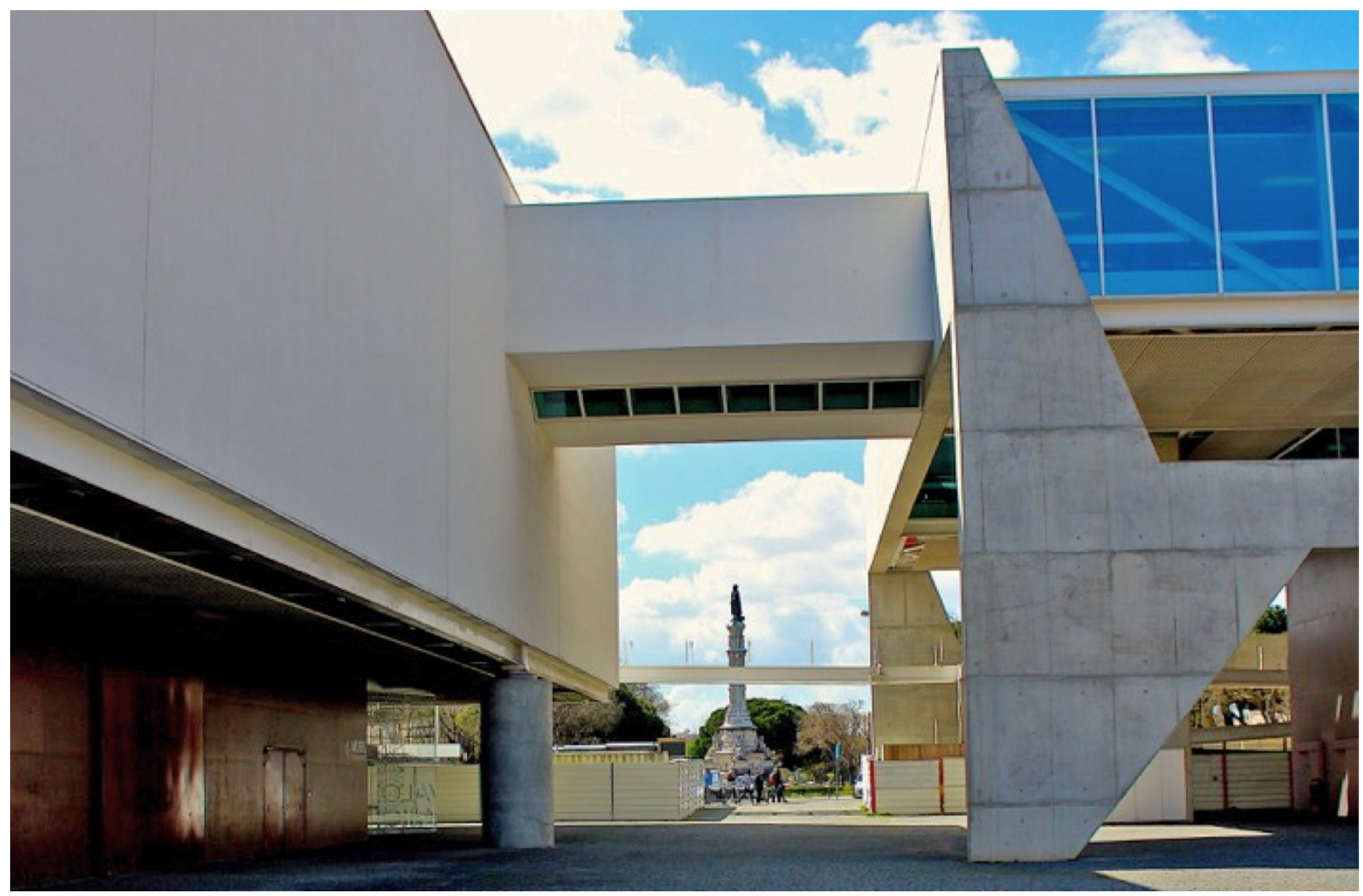

Figura 9: A estátua de Afonso de Albuquerque, enquadrada entre os dois volumes do Museu dos Coches. Fonte: Foto do autor, 2018. entorno, sem desvendá-los inteiramente. De dentro, aberturas estrategicamente localizadas direcionam as vistas, relacionam e, por vezes, confundem interior e exterior.

No recorte que redefine a vista da baía de Vitória; na sugestiva relação entre dentro e fora do prédio de apoio do museu lisboeta; no corredor linear conformado pelo atracamento invertido do teatro do Cais das Artes na borda d'água; na faixa de vidro que permite a quem atravessa a passarela espreitar os coches dentro do museu, emerge o potencial poético de ver e entrever o mundo a partir do abrigo seguro proporcionado pela arquitetura, "Porque para alguém perdido na praia como um náufrago, nenhuma baía é linda." (ROCHA 1998, in ROCHA; WISNIK, op. cit., p. 111)

\section{Sobre navios auxiliares}

No universo náutico que tanto encanta o arquiteto os navios auxiliares cumprem o papel de dar suporte à nave principal. De maneira análoga, em muitos projetos recentes de Mendes da Rocha a necessidade de abrigar funções complementares aos museus é resolvida por meio da criação de volumes de apoio, dando maior liberdade formal e espacial aos corpos principais. 
A destinação funcional complementar, no entanto, não significa desempenhar papel secundário no diálogo entre as partes que conformam a arquitetura. No Museu dos Coches, por exemplo, é a forma mais cuidadosamente trabalhada, enquanto no Cais das Artes, a escala do volume do teatro possui papel preponderante no equilíbrio do conjunto. Em ambos, mais que uma relação hierárquica, uma articulação de partes complementares estabelece a relação entre os volumes.

No caso português, o bloco de apoio abriga um pequeno auditório para 350 pessoas, caracterizado por uma espontaneidade provocativa que trata o acesso como um portão de garagem e troca os assentos estofados por "bancos de praça", uma brincadeira pop que complementa o jogo de contextualização exterior.

No museu capixaba, optou-se por dois volumes complementares: um menor, de $23 \times 23 \mathrm{~m}$ de base e conectado ao museu por passarelas suspensas, abriga as funções administrativas, enquanto outro, com planta quadrada de $69 \mathrm{~m}$ de lado, contém um grande teatro para aproximadamente 700 pessoas.

Outro tipo de edificação de apoio, o edifício-garagem cilíndrico, passou a ser uma proposta recorrente em projetos recentes de Mendes da Rocha. Além de aparecer como sugestão prototípica para a zona monumental de Belém, em um dado momento cogitou-se fazê-lo também em Vitória, onde estaria implantado sobre as águas do canal. (OTONDO, op. cit., p. 177) A mesma ideia complementa ainda os não executados projetos para a Universidade de Vigo (2005) e para o Instituto Tecnológico Vale de Desenvolvimento Sustentável (2010).

Tais recorrências suscitam a questão sobre o caráter prototípico e a sensibilidade a contextos específicos, intuitivamente contrapostos. A adaptação de um mesmo arranjo básico e a repetição de elementos e estratégias parecem indicar o desejo de contextualização sem abrir mão do potencial reprodutível da infraestrutura, presente em sua arquitetura desde os primeiros trabalhos.

No mesmo sentido, no recém-inaugurado SESC 24 de Maio, uma torre de apoio foi criada em um lote lateral agregado ao terreno para dar suporte às funções principais concentradas no antigo prédio da Mesbla.

Mas é na proposta para o anexo do Museu Nacional de Belas Artes do Rio de Janeiro que a figura do complemento ganha ares monumentais. Uma torre anódina levantase do pátio central do edifício eclético, confundindo-se com as demais existentes no entorno e coincidindo com a cota de altura do antigo edifício do Ministério da Educação e Saúde, de Lúcio Costa e equipe, situado a uma quadra dali.

\section{Sobre a exaltação da técnica}

Para Maria Isabel Villac, o Museu dos Coches é mais uma das arquiteturas que celebra as "formas alvas, brancas" que apareceram na obra de Mendes da Rocha a partir da cobertura para a Praça do Patriarca (1992-2002). Até então, a materialidade arcaica e contundente do concreto aparente dominava seu repertório. No museu português, combinam-se as materialidades do concreto, como principal suporte estrutural, e do aço, como elemento técnico preciso, limpo e silencioso, associação construtiva 
que havia sido experimentada pela primeira vez na obra do Ginásio Paulistano (195761) (VILLAC, 2016).

Pilares circulares de concreto sustentam o bloco do museu, deixando grandes balanços nos quatro cantos do edifício. Sobre eles, assenta-se a caixa em estrutura metálica composta por grandes treliças planas revestidas com chapas de alumínio brancas.

A materialidade lisa e industrialmente exata do metal não foi, no entanto, a intenção inicial do arquiteto. Algumas questões de ordem técnica exigiram adaptações consideráveis na obra final. Conforme Rui Furtado, engenheiro português responsável pela obra:

Vindo do Brasil - a terra do "concreto aparente"- era em betão que o edifício tinha sido imaginado. No entanto, ponderando os vãos de $50 \mathrm{~m}$, um prazo de construção muito curto como o que então estava definido, os aterros onde o edifício iria ser fundado, as ações sísmicas a ter em conta e a necessidade de albergar sistemas de controlo ambiental complexos e exigentes, sugerimos a mudança para um sistema construtivo leve - estrutura metálica monolítica, "agarrada" no centro e deslizante nos apoios periféricos e paredes ligeiras, em painéis de gesso cartonado. (FURTADO, in NEVES, op. cit., p. 134 e 138)

Note-se que no processo de adaptação altera-se a definição estrutural, mas prevalece a característica de projetar planos e volumes íntegros. A estrutura metálica por si não conforma o fechamento da edificação, restando então ao arquiteto a opção de expor seu verdadeiro desenho ou recobri-lo pela face exterior da estrutura.

Desde que incluiu as estruturas metálicas ao seu repertório técnico, Mendes da Rocha nunca as utilizou expostas externamente, como parte central da composição estética das obras. Ocasionalmente, apenas peças horizontais ou verticais, típicas do sistema arquitravado do concreto, são as partes que o arquiteto deixa visíveis, como no pórtico para a Praça do Patriarca. O complexo desenho diagonal de treliças planas e espaciais só aparecem na parte interna dos edifícios, como na loja Forma (1987) e no Poupatempo de Itaquera (1998). Externamente, apenas grandes planos, sempre silenciosamente brancos, são apresentados ao observador.

Nos projetos dos primeiros anos de sua carreira, a premissa da industrialização da construção costumava informar as soluções arquitetônicas, evitando revestimentos e explorando as próprias soluções construtivas na expressão plástica da obra. Nas exceções ao uso massivo do concreto como material único, marcava-se a diferença entre estrutura e fechamento, sem que um interferisse na identificação do outro.

No Museu dos Coches insinua-se a definição estrutural na parte externa através da exposição da viga metálica nas bordas horizontais do grande volume, e internamente nas aberturas de conexão entre os espaços interiores, cortadas acompanhando a diagonal da treliça. No entanto, trata-se de uma clara opção por não materializar a lógica abstrata do cálculo, raciocínio que agrada ao arquiteto e presente em muitas de suas obras mais representativas.

Uma lógica análoga define a dialética técnico-estética do Cais das Artes. Duas grandes vigas paralelas, cada uma delas sustentadas por três pilares, "penduram" as treliças 
metálicas planas que definem o desenho recortado das elevações longitudinais e ajudam a sustentar as lajes do interior do museu.

Na transição da seção retangular para a circular dos pilares próximos às extremidades do edifício, há um mecanismo para a absorção dos movimentos de deslizamento do volume suspenso, a exemplo do que ocorre com pilares de pontes. Um belo detalhe técnico do qual Mendes da Rocha sempre soube tirar proveito estético, também utilizado no Museu dos Coches e, iconicamente, no encontro entre os planos de muro e laje no MUBE.

Tal como no museu em Lisboa, optou-se por revestir a parte metálica da estrutura com placas de concreto pré-fabricadas, de forma a preservar a leitura integral da forma. Ainda que a separação entre a superestrutura de concreto e a parte revestida seja facilmente identificável, a percepção global sugere uma unidade material inexistente.

É certo que o acento técnico construído pela arquitetura moderna paulista sistematicamente valeu-se da hipertrofia estrutural, sempre justificada pelo discurso didático e simbólico sobre o funcionamento das estruturas. Parte dessa tradição, os projetos de Mendes da Rocha são conhecidos por levar ao limite as possibilidades da técnica, da qual extrai não somente a forma como também seu discurso.

A inserção de novos materiais e técnicas construtivas redefinem esteticamente a materialidade bruta e artesanal que marca grande parte de suas obras. Tanto a aparência industrial do metal quanto a textura regular impressa pelas modernas fôrmas de concretagem configuram uma materialidade nova, destituída das conotações políticas que outrora relacionavam o trabalho humano às marcas impressas na obra.

A partir do MUBE, um museu sem volume aparente, muitas de suas obras testam os limites da desmaterialização, sem perda da sugestão de arrojo estrutural. A ilusória espessura epidérmica da loja Forma (1987) e a flutuante Capela de São Pedro (1987), além da já citada cobertura para Praça do Patriarca, são exemplares dessa atitude.

Se nos museus de Vitória e Lisboa a potente definição tectônica não explicita o mecanismo de sua construção - chegando a causar certa estranheza e incômodo-, a potência discursiva é concentrada no consagrado recurso paulista de negar o peso de grandes volumes suspensos ao, poeticamente, "fazer cantar os pontos de apoio".

Em um nível conceitual mais amplo, profundo e menos visível, a exaltação à técnica reside ainda na correspondência precisa entre espacialidade e definição estrutural. É notável sua coerência ao buscar na técnica a medida de uma arquitetura que se define pelo mínimo necessário, sem deixar de ser espacial e formalmente magnífica, nem escorregar na embriaguez formal possibilitada pelos recursos de projeto e construção disponíveis atualmente.

Mendes da Rocha expõe apenas aquilo que lhe interessa, como se ao manter a limpidez formal, mantivesse a legilibilidade de um discurso que não quer dizer tudo, mas somente o que considera necessário.

Você não pode ser prolixo, pois corre o risco de arruinar o discurso, de diluí-lo. Não se bebe o veneno aos litros. E os bons perfumes são conservados em pequenos frascos. (...) (ROCHA, in PISANI, 2013, p. 42) 


\section{Encerrando o assunto}

Ainda que restrito a dois exemplares específicos, o diálogo travado entre o Museu dos Coches e o Cais das Artes expõe as questões estruturadoras do discurso que ampara a arquitetura de Paulo Mendes da Rocha.

Em ambos, o elegante traço que caracteriza as obras do arquiteto aflora em perfeita sintonia com as características que celebrizaram a arquitetura moderna paulista: a síntese entre forma e estrutura, a suspensão do solo, poucos e expressivos pontos de apoio, a continuidade com o contexto.

É notável a tenacidade da sintonia entre pensamento e projeto ao longo da trajetória "monumental" de Mendes da Rocha, cujos louros do reconhecimento quase unânime não degeneram na reedição de fórmulas outrora exitosas. Ao contrário, a experiência de sua longevidade parece encorajá-lo a enfrentar desafios renovadores.

Sua inteligência inquieta e curiosidade democrática agregam novos conhecimentos e referências ao longo do tempo, tornando ainda mais sólidas as bases e a atualidade de sua arquitetura. Conforme observa Guilherme Wisnik:

O que acarreta uma situação curiosamente singular: sendo ele um arquiteto evidentemente moderno, vemos que o seu pensamento, no entanto, é em grande medida informado pela teoria pós-moderna. O que distingue fortemente Paulo Mendes da Rocha de seus pares, tais como Vilanova Artigas e Oscar Niemeyer. Talvez venha justamente daí, me parece, algo de sua espantosa originalidade. (WISNIK, in ROCHA; WISNIK, op. cit., p. 110)

Muito haveria que se dizer também sobre sua intensa e frutífera parceria com escritórios de arquitetos da nova geração paulista, entre os quais o Metro, colaborador no projeto de Vitória, e o MMBB, coautor do museu português juntamente com o português Ricardo Bak Gordon.

Por não perder a vigência e a coerência naquilo que é essencial, a semântica e a sintaxe do discurso do velho mestre seguem firmes como um farol a guiar boa parte da nova safra de arquitetos brasileiros.

\section{Agradecimentos}

Fundação de Amparo à Pesquisa do Estado de São Paulo (FAPESP), processo $n^{\circ}$ 2016/21108-2.

\section{Referências bibliográficas}

AA VV. Rino Levi. Milano: Edizioni di Comunità, 1974.

ARGENTI, Maria. La linea del cielo e la linea di terra nell'architettura paulista. Rassegna di architettura e urbanística: La Scuola di São Paulo in Brasile. Concezione strutturale e ideazione architettonica. Milão, Ano XLI/III, n. 142/143, jan./ago. 2014.

ARTIGAS, Rosa (org.). Paulo Mendes da Rocha. São Paulo: Cosac \& Naify, 2000. 
BASTOS, Maria Alice Junqueira. Paulo Mendes da Rocha. Breve relato de uma mudança. Arquitextos, São Paulo, ano 11, n. 122.01, Vitruvius, jul. 2010. Disponível em:<http://www.vitruvius. com.br/revistas/read/arquitextos/11.122/3472>. Acesso em: 30/11/2017.

FORSTER, Kurt. W. Why are some buildings more interesting than others? Harvard Design Magazine, Cambridge, n. 7, p. 104-115, winter/spring 1999.

FRANK, Klaus, GIEDION, Sigfried. Affonso Eduardo Reidy. bauten un projekte. Stuttgart: Gerd Hatje, 1960.

LE CORBUSIER. Precisões sobre um estado presente da arquitetura e do urbanismo. São Paulo: Cosac \& Naify, 2004.

MONTANER, Josep Maria, VILLAC, Maria Isabel (Org.) Mendes da Rocha. Barcelona: Gustavo Gili, 1996.

NEVES, José Manuel das (ed.). Museu Nacional dos Coches. Lugar, projeto e obra. Lisboa: Uzina Books, 2015.

OTONDO, Catherine. Desenho e espaço construído: relações entre pensar e fazer na obra de Paulo Mendes da Rocha. 2013. Tese (Doutorado em Arquitetura) - Faculdade de Arquitetura e Urbanismio, Universidade de São Paulo, São Paulo.

PAPADAKI, Stamo. The Work of Oscar Niemeyer. New York: Reinhold, 1950.

Oscar Niemeyer. Works in progress. New York: Reinhold, 1956.

. Oscar Niemeyer. New York: George Braziller, 1960.

PIÑón, Helio. Paulo Mendes da Rocha. São Paulo: Romano Guerra, 2002.

PISANI, Daniele. Paulo Mendes da Rocha: obra completa. São Paulo: Gustavo Gili, 2013.

ROCHA, Paulo Mendes da. Museu Nacional dos Coches, Lisboa. Projetos, São Paulo, ano 16, n. 183.02, Vitruvius, mar. 2016. Disponível em: <http://www.vitruvius.com.br/revistas/read/ projetos/16.183/5961>. Acesso em: 30/11/2017.

América, natureza e cidade/ Paulo Mendes da Rocha; com Maria Isabel Villac. São Paulo: Estação Liberdade, 2012.

Entrevista a Ivo Giroto. 21/09/2017.

ROCHA, Paulo Mendes da; WISNIK, Guilherme (org). Encontros: Paulo Mendes da Rocha. Rio de Janeiro: Beco do Azougue, 2012.

SPIRO, Annette. Paulo Mendes da Rocha: bauten und projekte. Zürich: Niggli, 2002.

TELLES, Sophia da Silva. Museu da Escultura. Revista AU, São Paulo, n. 32, p. 44-51, out./nov. 1990.

VILLAC, Maria Isabel. Museu dos Coches em Lisboa, de Paulo Mendes da Rocha, MMBB Arquitetos e Bak Gordon Arquitectos. Vitruvius Drops 101.06, ano 16, fev. 16. Disponível em: <http:// www.vitruvius.com.br/revistas/read/drops/17.101/5960>. Acesso em: 30/11/2017.

. La construcción de la mirada. Naturaleza, ciudad y discurso em la arquitectura de Paulo Mendes da Rocha. 2002. Tese(Doutorado em Teoria e História de la Arquitectura), Universitat Politècnica de Catalunya, Barcelona.

WAISMAN, Marina. O interior da história: historiografia arquitetônica para uso de latino-americanos. São Paulo: Perspectiva, 2013. 